\title{
Title: A new multi-sensor integrated index for drought monitoring
}

Authors: Wenzhe Jiao ${ }^{\mathrm{a}}$, Lixin Wang ${ }^{\mathrm{a}}$, Qing Chang ${ }^{\mathrm{b}}$, Kimberly A. Novick ${ }^{\mathrm{c}}$ Chao Tian ${ }^{\mathrm{a}}$

a. Department of Earth Sciences, Indiana University-Purdue University Indianapolis (IUPUI), Indianapolis, IN 46202,

USA

b. Department for Microbiology and Plant Biology, Center for Spatial Analysis, University of Oklahoma, Norman, OK

73019, USA

c. School of Public and Environmental Affairs, Indiana University Bloomington, Bloomington, IN 47405, USA

* Correspondence to: Lixin Wang (lxwang@iupui.edu)

Department of Earth Sciences

Indiana University-Purdue University Indianapolis (IUPUI)

Indianapolis, IN 46202, USA

Office phone number: 317-274-7764

This is the author's manuscript of the article published in final edited form as:

Jiao, W., Tian, C., Chang, Q., Novick, K. A., \& Wang, L. (2019). A new multi-sensor integrated index for drought monitoring. Agricultural and Forest Meteorology, 268, 74-85. https://doi.org/10.1016/j.agrformet.2019.01.008 


\section{Abstract}

Drought is one of the most expensive but least understood natural disasters. Remote sensing based integrated drought indices have the potential to describe drought conditions comprehensively, and multi-criteria combination analysis is increasingly used to support drought assessment. However, conventional multi-criteria combination methods and most existing integrated drought indices fail to adequately represent spatial variability. An index that can be widely used for drought monitoring across all climate regions would be of great value for ecosystem management. To this end, we proposed a framework for generating a new integrated drought index applicable across diverse climate regions. In this new framework, a local ordered weighted averaging (OWA) model was used to combine the Temperature Condition Index (TCI) from the Moderate-resolution Imaging Spectroradiometer (MODIS), the Vegetation Condition Index (VCI) developed using the Vegetation Index based on Universal Pattern Decomposition method (VIUPD), the Soil Moisture Condition Index (SMCI) derived from the Advanced Microwave Scanning Radiometer-Earth Observation System (AMSR-E), and the Precipitation Condition Index (PCI) derived from the Tropical Rainfall Measuring Mission (TRMM). This new index, which we call the "Geographically Independent Integrated Drought Index (GIIDI)," was validated in diverse climate divisions across the continental United States. Results showed that GIIDI was better correlated with in-situ PDSI, Z-index, SPI-1, SPI-3 and SPEI-6 (overall r-value $=0.701,0.794,0.811,0.733,0.628 ; \mathrm{RMSE}=1.979,0.810,0.729,1.049$ and 1.071, respectively) when compared to the Microwave Integrated Drought Index (MIDI), Optimized Meteorological Drought Index (OMDI), Scaled Drought Condition Index (SDCI), PCI, TCI, SMCI, and VCI. GIIDI also performed well in most climate divisions for both short-term and long-term drought monitoring. Because of the superior performance of GIIDI across diverse temporal and spatial scales, GIIDI has considerable potential for improving our ability to monitor drought across a range of biomes and climates.

Keywords: CONUS, Drought, GIIDI, Local OWA, Remote sensing 


\section{Introduction}

Drought is a naturally occurring hazard with profound consequences for socioeconomic development and ecosystems. It results in famines and crop failures that cause global economic losses of 6-8 billion dollars, on average, each year (Pandey et al., 2007; Sheffield et al., 2009; Zhou et al., 2012). Drought reduces ecosystem $\mathrm{CO}_{2}$ uptake and increases atmospheric $\mathrm{CO}_{2}$ concentrations $(\mathrm{Ciais}$ et al., 2005; Mk et al., 2011; Vetter et al., 2008). Long and severe droughts also trigger lasting changes in vegetation canopy structure and function (Donohue et al., 2013; Novick et al., 2016; Parida et al., 2008). International research on droughts is of increasing importance since the frequency and consequences of droughts are expected to intensify in the future (Halwatura et al., 2017; Keyantash and Dracup, 2004; Wilhelmi and Wilhite, 2002; Zhou et al., 2012).

Droughts are broadly classified into four types: (1) "Meteorological drought" is a period of months or even years with abnormally low precipitation; (2) "Agricultural drought" occurs when soil moisture is reduced below the level at which plant function becomes impaired; (3) "Hydrological drought" occurs when streamflow, groundwater, or total water storages are below long-term means; and (4) "Socioeconomic drought" describes moisture deficits that cause the demand of certain commodities to exceed supply (Du et al., 2013; Hao et al., 2015; Quiring and Ganesh, 2010; Rhee et al., 2010). This classification acknowledges that a range of factors, including topography, antecedent conditions, vegetation type, and land use, work together to determine the consequences of precipitation shortfalls, and that a deficit of a given magnitude will not affect all landscapes in the same way. However, in reality, it can be difficult to neatly classify a drought event into a single category. For example, an agricultural drought can become a socioeconomic drought if droughtdriven declines in plant function reduce crop yield. Similarly, moisture deficits that affect plant function also often affect outflow, so that agricultural and hydrologic drought occur in combination. Thus, efforts to diagnose and monitor drought may benefit from holistic frameworks that consider a range of variables that affect local meteorology, hydrology, and plant function. 
Historically, droughts have been monitored and classified from frameworks based on stationbased point observations (AghaKouchak et al., 2015; Mishra and Singh, 2010; Zhang and Jia, 2013). However, in regions with limited sampling gauges, station-based based drought indices are not sufficient to characterize drought conditions. In situations like this, remote sensing can be a very useful tool, since it provides continuous and consistent observations of relevant variables linked to ecosystem status and the hydrologic cycle (Lu et al., 2016; Rhee and Im, 2017; Rhee et al., 2010; Wu et al., 2013; Zhang et al., 2017a). A suite of remotely-sensed indices already exist, each with different emphasis. For instance, the Precipitation Condition Index (PCI), which incorporates precipitation information from the Tropical Rainfall Measuring Mission (TRMM) data, and the Temperature Condition Index (TCI) derived from Land Surface Temperature (LST) data, are commonly used remote sensing drought indexes that have a clear climatological perspective (Hao et al., 2015; Rhee et al., 2010; Zhang and Jia, 2013). From the ecological perspective, drought can be estimated based on observed changes in vegetation growth indicators (e.g., Normalized Difference Vegetation Index (NDVI) and Vegetation Condition Index (VCI)) from remotely sensed data (Di et al., 1994; Hielkema et al., 1986; Kogan, 1995a; Rouse et al., 1974).

However, in isolation, station-based or remotely-sensed drought indices may fail to capture key aspects of drought evolution that are of interest to land and water resource managers. For example, declines in plant function may not be immediately apparent if they do not affect greenness or leaf area index (LAI). In this scenario, an index based only on vegetation condition (e.g. from remotelysensed greenness) may not detect drought-related reductions in plant function that are not manifested as a change in leaf abundance or color (Zhang et al., 2016). As another example, drought conditions can be aggravated by high temperature and low relative humidity, which can impact meteorology, hydrology, and plant function (Hao et al., 2017; Park et al., 2016) independently of precipitation deficits. In this case, an index based only on precipitation would not be able to characterize hydrologic stress linked to rising vapor pressure deficit (VPD) during a heat wave (Almeida and Landsberg, 2003; Stocker et al., 2018). 
Thus, a single drought index may not be sufficient to capture the complex processes and diverse impacts of drought (Hao and Singh, 2015). While, land and water resource managers may have the option of consulting a range of drought indices (i.e. remotely sensed, station-driven, etc.) to inform their forecasts and drought response strategies. However, this approach is challenged by the associated diversity of choice, and logistically difficulty of accessing information from multiple platforms. Thus, efforts to diagnose and monitor drought benefit considerably from the development of holistic frameworks that consider a range of variables that affect local meteorology, hydrology, and plant function. A clear example of such an "integrated" approach is the US Drought Monitor (USDM), which combines information from stations and satellites together with expert knowledge, and is widely used by US federal management agencies. However, due to its reliance on station-information and satellites, the USDM approach is not applicable to the vast areas of land globally where station data and expert knowledge are not readily available.

To this end, integrated remote-sensing drought indices, which are based on multiple perspectives, are urgently needed, and several studies have already made strides in developing them. Table 1 lists a summary of several commonly used integrated drought indices. For example, the Microwave Integrated Drought Index (MIDI), which integrates Soil Moisture Condition Index (SMCI), PCI and TCI, has been shown to be an optimum drought index for meteorological drought monitoring over semiarid regions in China (Zhang and Jia, 2013). Similarly, the Scaled Drought Condition Index (SDCI) combines PCI with TCI and VCI for agricultural drought monitoring in both arid/semiarid and humid states in the United States (U.S.) (Rhee et al., 2010). The Optimized Meteorological Drought Index (OMDI) and Optimized Vegetation Drought Index (OVDI), which are based on VCI, TCI, PCI, and SMCI, have been investigated as tools to detect and monitor both agricultural and meteorological drought in Southwest China (Hao et al., 2015). Finally, the Synthesized Drought Index (SDI), which was developed using TCI, PCI, and VCI, was shown to be a good indicator for agricultural drought monitoring in Shandong province in China (Du et al., 2013).

However, the usefulness of these integrated, remotely-sensed indices is limited considerably by 5 
the fact that they were established and evaluated for a specific climate or geographic location. As shown in Table 1, the study areas over which the indices were developed are typically confined to one or two climate regions. Few of these indices were developed under diverse environmental conditions covering large spatial scales. This geographic constraint could lead to poor performance if certain indices are applied in climate regions that are much different from those in which they were developed (Quiring and Ganesh, 2010; Zhang et al., 2017a). Another major issue is that the parameters of the composition methods are typically viewed as spatially homogeneous (Hao et al., 2015; Zhang and Jia, 2013). For example, it is often assumed that all the sub-areas of a particular study area contribute the same weight for a particular single index, and an empirical linear combination method is used to derive a relationship that is believed to be uniformly applicable across the study area (Malczewski and Liu, 2014; Tang et al., 2018). This type of integration is straightforward to implement and has gained popularity in recent developments of multivariate drought indices (AghaKouchak, 2015). However, this type of integration may not be applicable to characterize the covariability of drought related indices, since it may miss local details that can be significant if the relationship of the related indices is spatially non-stationary (AghaKouchak, 2015). A third issue is that satellite observations are subject to various uncertainties linked to errors in retrieval algorithms, data acquisition, data post-processing, and infrequent overpasses. (AghaKouchak et al., 2012; Damberg and AghaKouchak, 2014; Hong et al., 2006). These challenges have historically motivated the use of in-situ data when developing drought indices. However, in regions with limited ground observation sites, inadequacy of in-situ data has hampered drought monitoring. Thus, a reliable remote sensing based integrated drought index which is independent of in-situ data is of great importance.

To address these issues, the objective of this study is to develop and evaluate a new integrated drought index based on multi-sensor remote sensing data for drought monitoring under different climate conditions. An index like this could facilitate drought response and mitigation planning, particularly in areas where station-based data are sparse. Our approach uses local ordered weighted 6 
averaging (OWA) to integrate single remote sensing based drought indices. Local OWA was selected because it can accommodate heterogeneities in the land surface by using different weights in different parts of the study area for a particular single index. Thus, the newly developed index can be applied to diverse climate regions. We named the new index Geographically Independent Integrated Drought Index (GIIDI) indicating its universal applicability for diverse climate regions. To evaluate the performance of GIIDI, it was compared to integrated drought indices such as MIDI and OMDI, as well as single drought indices such as PCI, TCI, VCI and SMCI. We focus on comparison on the continental US, where USDM data can serve as a useful reference for validation. 
1 Table 1 Summary of studies using multivariate analysis for drought estimation, including drought type, experiment region and year, data source and methodology.

\begin{tabular}{|c|c|c|c|c|c|}
\hline Index & Type & Study area & Data & Method & Reference \\
\hline ESI & $\begin{array}{l}\text { Agricultural } \\
\text { drought }\end{array}$ & Brail & $\begin{array}{l}\text { MODIS LAI; MODIS LST; MERRA; } \\
\text { TRMM }\end{array}$ & $\begin{array}{l}\text { Integrated multisource data using } \\
\text { evaporative stress mechanism }\end{array}$ & (Anderson et al., 2016) \\
\hline ISDI & $\begin{array}{l}\text { Agricultural } \\
\text { drought }\end{array}$ & Mid-eastern China & $\begin{array}{l}\text { MODIS NDVI; MODIS LST; ecological } \\
\text { zoning; AWC; irrigation water } \\
\text { management distribution; DEM }\end{array}$ & $\begin{array}{l}\text { Integrated multisource data mining } \\
\text { technology (CART) }\end{array}$ & (Wu et al., 2013) \\
\hline MDI & $\begin{array}{l}\text { Hydrological } \\
\text { drought }\end{array}$ & Texas, U.S. & $\begin{array}{l}\text { NOAA precipitation; runoff; actual } \\
\text { evapotranspiration }\end{array}$ & $\begin{array}{l}\text { MDI extraction based } \\
\text { on KECA }\end{array}$ & (Rajsekhar et al., 2015) \\
\hline MIDI & $\begin{array}{l}\text { Meteorological } \\
\text { drought }\end{array}$ & Northern China & $\begin{array}{l}\text { AVHRR LST;AMSR-E soil moisture; } \\
\text { TRMM precipitation }\end{array}$ & $\begin{array}{l}\text { Combined TCI, SMCI and PCI using } \\
\text { empirical weights }\end{array}$ & (Zhang and Jia, 2013) \\
\hline MSDI & $\begin{array}{l}\text { Agricultural } \\
\text { drought }\end{array}$ & $\begin{array}{l}\text { California and North } \\
\text { Carolina, U.S. }\end{array}$ & CPC precipitation; $\mathrm{CPC}$ soil moisture & $\begin{array}{l}\text { Combined SPI and SSI using } \\
\text { copulas-based conjunction }\end{array}$ & (Hao and Aghakouchak, 2013) \\
\hline OMDI & $\begin{array}{l}\text { Meteorological } \\
\text { drought }\end{array}$ & Southwest of China & $\begin{array}{l}\text { AVHRR LST;AMSR-E soil moisture; } \\
\text { TRMM precipitation }\end{array}$ & $\begin{array}{l}\text { Combined TCI, SMCI and PCI by } \\
\text { Constrained Optimization }\end{array}$ & (Hao et al., 2015) \\
\hline OVDI & $\begin{array}{l}\text { Vegetation } \\
\text { drought }\end{array}$ & Southwest of China & $\begin{array}{l}\text { AVHRR LST; AVHRR NDVI; AMSR-E } \\
\text { soil moisture; TRMM precipitation }\end{array}$ & $\begin{array}{l}\text { Combined VCI, TCI, SMCI and PCI } \\
\text { by Constrained Optimization }\end{array}$ & (Hao et al., 2015) \\
\hline PADI & $\begin{array}{l}\text { Agricultural } \\
\text { drought }\end{array}$ & $\begin{array}{l}\text { Hubei, Yunnan and } \\
\text { Hebei, China }\end{array}$ & $\begin{array}{l}\text { GPCC precipitation; GLDAS soil } \\
\text { moisture; AVHRR NDVI; }\end{array}$ & $\begin{array}{l}\text { Evolution Process based Multi- } \\
\text { sensor Collaboration framework }\end{array}$ & (Zhang et al., 2017b) \\
\hline
\end{tabular}




\begin{tabular}{|c|c|c|c|c|c|}
\hline SDCI & $\begin{array}{l}\text { Agricultural } \\
\text { drought }\end{array}$ & $\begin{array}{l}\text { Arizona and New } \\
\text { Mexico, North and } \\
\text { South Carolina, U.S. }\end{array}$ & $\begin{array}{l}\text { AVHRR LST; AVHRR; TRMM } \\
\text { precipitation }\end{array}$ & $\begin{array}{l}\text { Combined VCI, TCI and PCI by } \\
\text { empirical weights }\end{array}$ & (Rhee et al., 2010) \\
\hline SDI & $\begin{array}{l}\text { Agricultural } \\
\text { drought }\end{array}$ & Shandong, China & $\begin{array}{l}\text { MODIS LST; MODIS NDVI, MODIS } \\
\text { reflectance; TRMM precipitation }\end{array}$ & Combined VCI, TCI and PCI by PCA & (Du et al., 2013) \\
\hline VegDRI & $\begin{array}{l}\text { Vegetation } \\
\text { drought }\end{array}$ & North-Central U.S. & $\begin{array}{l}\text { MODIS NDVI; MODIS LST; ecological } \\
\text { zoning; AWC; irrigation water } \\
\text { management distribution; DEM }\end{array}$ & $\begin{array}{l}\text { Integrated multisource data mining } \\
\text { technology (CART) }\end{array}$ & (Brown et al., 2008) \\
\hline HSMDI & $\begin{array}{l}\text { Meteorological } \\
\text { and agricultural } \\
\text { drought }\end{array}$ & Korean Peninsula & $\begin{array}{l}\text { MODIS LST, NDVI, EVI, Albedo, LAI, } \\
\text { ET; TRMM precipitation and AMSR-E } \\
\text { soil moisture }\end{array}$ & $\begin{array}{l}\text { Downscaled soil moisture using a } \\
\text { Random forest approach }\end{array}$ & (Park et al., 2017) \\
\hline $\begin{array}{l}\text { VegDRI- } \\
\text { Canada }\end{array}$ & $\begin{array}{l}\text { Vegetation } \\
\text { drought }\end{array}$ & $\begin{array}{l}\text { Canadian territory } \\
\text { south of } 60^{\circ} \mathrm{N}\end{array}$ & $\begin{array}{l}\text { NDVI, land cover/land use, soil data and } \\
\text { in-situ climate data }\end{array}$ & $\begin{array}{l}\text { Integrated multisource data mining } \\
\text { technology (CART) }\end{array}$ & (Tadesse et al., 2017) \\
\hline
\end{tabular}




\section{Data}

Datasets collected both in-situ and with remote sensing were used to assess the performance of our newly developed drought index in various climate divisions over the continental United States (CONUS) from 2002 to 2011 (when AMSR-E satellite ended). The analysis in this study focused primarily on the months from April to October in order to avoid complications arising from snow and ice in winter.

\subsection{In-situ based drought indices}

Monthly in-situ drought indices, including PDSI, moisture anomaly index (Z-index), and Standardized Precipitation Index (SPI), were selected as the reference data for evaluating GIIDI. These in-situ drought indices were obtained from the NOAA's National Climatic Data Center (NCDC-NOAA) repository for 344 climatic divisions in the CONUS (http://www1.ncdc.noaa.gov/pub/data/cirs/), and have been used in previous studies to evaluate remote sensing drought indices (Brown et al., 2008; Caccamo et al., 2011; Ji and Peters, 2003; Jiao et al., 2016; Rhee et al., 2010; Zhang et al., 2017a).

\subsection{Remote sensing data}

GIIDI was established by integrating MODIS- based VCI and TCI, AMSR-E based SMCI, and TRMM based PCI. The VCI, which is derived from Vegetation Index based on the Universal Pattern Decomposition method (VIUPD), was calculated using MODIS land surface data (MOD09A1) downloaded from the Land Processes Distributed Active Center (LPDAAC; http://lpdaac.usgs.gov/). MODIS Land Surface Temperature (LST) data (MOD11A2) was used to calculate TCI and it was obtained from the National Aeronautics and Space Administration's (NASA) earth observing system data and information system (EOSDIS; http://reverb.echo.nasa.gov). We composited the MOD11A2 and MOD09A1 into monthly data according to data quality flags and the number of days in each 
month. PCI was calculated based on TRMM 3B43 data, which provides an estimate of monthly precipitation. Data from 2002 to 2011 is available at the NASA Data and Information Services Center (DISC) (http://mirador.gsfc.nasa.gov/). The AMSR-E product was used to calculate SMCI. The AMSR-E data was available from 2002 to 2011 and could be obtained from Vrije Universtiteit Amsterdam (http://nsidc.org/)

\subsection{Other data}

A number of other datasets were used to validate the applicability of the GIIDI for drought monitoring in different climate divisions across the CONUS. USDM data was chosen as reference for evaluating GIIDI, since it combines information from multiple ground-observation based drought indicators and local reports from state climatologists and observers throughout the country (Hayes et al., 2012). It is worth noting that USDM is a categorical index, with the following classifications: abnormally dry (D0), moderate drought (D1), severe drought conditions (D2), extreme drought (D3), and exceptional drought (D4). More detailed information about USDM can be found at http://drought.unl/dm/.

\section{Methodology}

The methodology is illustrated in Fig. 1. First, data were prepared and pre-processed. During this step, MOD11A2 data was used to composite 8-day LST to the monthly data. It should be noted that VIUPD was used to calculate VCI instead of the commonly used NDVI, because previous work indicates that VIUPD-based VCI has better performance for drought monitoring in more climate regions than NDVI-based VCI (Jiao et al., 2016). More detailed information about the calculation of VIUPD is available in Zhang et al. (2007). In the second step, the condition indices (TCI, VCI, PCI and SMCI) were calculated using the multi-source remote sensing data mentioned in the first step. The condition indices were scaled from 0 to 1 for each pixel, within the period from April to October (2002 -2011). The third step was to composite the single indices together. In this step, we used a local 
OWA model to combine TCI, VCI, PCI and SMCI (see section 3.2 for more details). As a final step, we used in-situ drought indices to evaluate the correlation between the in-situ drought indices and GIIDI in different climate divisions.

\subsection{Scaled remote sensing indices}

Table 2 shows detailed information about the remote sensing based drought indices used in this study. TCI, PCI, VCI and SMCI were are single drought indices incorporated into the GIIDI, while MIDI and OMDI were used to evaluate the performance of GIIDI. All these indices were calculated from April to October for the period 2002-2011.

Table 2 Descriptions of remote sensing based drought indices used in this study. The data source column indicates the satellite name or single drought indices. For the integrated drought indices (MIDI, OMDI), the method column indices how the weights of single drought indices were determined.

\begin{tabular}{|c|c|c|c|}
\hline $\begin{array}{l}\text { Drought } \\
\text { index }\end{array}$ & Data source & Method & Source \\
\hline VCI & MODIS & $\left(\right.$ VIUPD $\left._{\mathrm{ikj}}-\mathrm{VIUPD}_{\mathrm{i}, \min }\right) /\left(\mathrm{VIUPD}_{\mathrm{i}, \max }-\mathrm{VIUPD}_{\mathrm{i}, \min }\right)$ & (Kogan, 1995b) \\
\hline TCI & MOIDS & $\left(\mathrm{LST}_{\mathrm{i}, \max }-\mathrm{LST}_{\mathrm{ijk}} \mathrm{k} /\left(\mathrm{LST}_{\mathrm{i}, \max }-\mathrm{LST}_{\mathrm{i}, \min }\right)\right.$ & (Kogan, 1997) \\
\hline SMCI & AMSR-E & $\left(\mathrm{SM}_{\mathrm{ikj}}-\mathrm{SM}_{\mathrm{i}, \min }\right) /\left(\mathrm{SM}_{\mathrm{i}, \max }-\mathrm{SM}_{\mathrm{i}, \min }\right)$ & (Zhang and Jia, 2013) \\
\hline PCI & TRMM & $\left(T_{R M M} M_{i k j}-T_{R M M} M_{i, \min }\right) /\left(T R M M_{i, \max }+T_{R M M} M_{i, \min }\right)$ & (Rhee et al., 2010) \\
\hline MIDI & TCI, SMCI, PCI & Empirical weights & (Zhang and Jia, 2013) \\
\hline OMDI & TCI, SMCI, PCI & Constrained optimization & (Hao et al., 2015) \\
\hline GIIDI & VCI, TCI, SMCI, PCI & Local OWA & This study \\
\hline
\end{tabular}

Note: LST $_{\mathrm{ijk}}, \mathrm{SM}_{\mathrm{ijk}}, \mathrm{TRMM}_{\mathrm{ijk}}$ - monthly LST, SM, TRMM for pixel i, in month $\mathrm{j}$, for year k, respectively. $\mathrm{LST}_{\mathrm{i}, \mathrm{min}}, \mathrm{SM}_{\mathrm{i}, \mathrm{min}}$, TRMM $_{\mathrm{i}, \min }$-multi-year minimum LST, SM, TRMM, respectively, for pixel i. $\mathrm{LST}_{\mathrm{i}, \max }, \mathrm{SM}_{\mathrm{i}, \max }, \mathrm{TRMM}_{\mathrm{i}, \max }$-multi-year maximum LST, SM, TRMM, respectively. 


\subsection{GIIDI development}

The selection of single drought indices for establishing the integrated drought index is an important component of our approach. Previous studies have indicated that single drought indices based on time series analysis (PCI, TCI, VCI and SMCI) performed better than other types of single drought indices such as the Perpendicular Drought Index (PDI), Modified Perpendicular Drought Index (MPDI) and temperature Vegetation Dryness Index (TVDI) (Zhang et al., 2017a). PCI is derived from the scaled precipitation information based on TRMM data, TCI is derived from land surface temperature information, VCI describes conditions related to vegetation growth, and the SMCI is soil moisture condition from AMSR-E data. These indices are not fully correlated with each other, which motivated us to use PCI, SMCI, VCI and TCI to inform GIIDI.

The ordered weighted averaging (OWA), which was developed by Yager (1993), provides a general class of parameterized aggregation operators between the minimum and maximum. In the OWA, criteria weights and order weights are applied. Criteria weights $\left(w_{1}, w_{2} \ldots w_{n}, 0 \leq w_{k} \leq 1\right.$, and $\left.\sum_{k=1}^{n} w_{k}=1\right)$ determines the relative importance of evaluation criteria, while order weights $\left(\lambda_{1}\right.$, $\lambda_{2}, \ldots, \lambda_{n}, 0 \leq \lambda_{k} \leq 1$, and $\sum_{k=1}^{n} \lambda_{k}=1$ ) indicate the degree of tradeoff between "ANDness" (requiring all the criteria to be satisfied) and "ORness" (requiring at least one of the criteria to be satisfied) (Yager, 1993).

However, one issue challenging the OWA model is spatial homogeneity of its weights, irrespectively of spatial heterogeneity across the landscape. To address this issue, Malczewski and Liu (2014) developed the local OWA model based on the range-sensitivity principle (Fischer, 1995). The local OWA model subdivides the study area into different neighborhoods. A moving window approach was used to define the neighborhoods, then the weights of each single drought index were allocated based on the order of the index values between the minimum and maximum in each moving window. Hence, for the given set of single drought indices $a_{i 1}, a_{i 2}, \ldots, a_{i n}$ at the $i^{\text {th }}$ location $(i=1,2, \ldots$, n), GIIDI was calculated using the local OWA model based on the following equations: 


$$
O W A_{i q}=\sum_{k=1}^{n} \frac{\lambda_{k} u_{k q} z_{i k q}}{\sum_{k=1}^{n} \lambda_{k} u_{k q}}
$$

where $\mathrm{OWA}_{\mathrm{iq}}$ is the OWA value of the $\mathrm{i}^{\text {th }}$ pixel estimated in the $\mathrm{q}^{\text {th }}$ neighborhood; $\lambda_{\mathrm{k}}$, is the order weight associated with the $\mathrm{k}^{\text {th }}$ single drought index among PCI, TCI, SMCI and VCI; $\mathrm{z}_{\mathrm{i} 1 \mathrm{q}} \geq \mathrm{z}_{\mathrm{i} 2 \mathrm{q}}$ $\geq \cdots \geq$ Zinq $_{\text {in }}$ is obtained by reordering the normalized values according to local value function $v\left(a_{i k}^{q}\right)$ (see Equation (3)); $u_{k q}$ is the reordered $w_{k q}$ according to $z_{i k q}$. The local criterion weight, $w_{k q}$, is defined as:

$$
w_{k q}=\frac{w_{k q}^{*}}{\sum_{k=1}^{n} w_{k q}^{*}}, 0 \leq w_{k q} \leq 1, \text { and } \sum_{k=1}^{n} w_{k q}=1
$$

where $w_{k q}^{*}=\left(w_{k} r_{k q} / r_{k}\right)$ is the local weight of the $\mathrm{k}^{\text {th }}$ single drought index in the $\mathrm{q}^{\text {th }}$ neighborhood.

$$
v\left(a_{i k}^{q}\right)=\left\{\begin{array}{l}
\frac{a_{i k}^{q}-\min _{i q}\left(a_{i k}^{q}\right)}{\max _{i q}\left(a_{i k}^{q}\right)-\min _{i q}\left(a_{i k}^{q}\right)} \text { for the } \mathrm{k}^{\text {th }} \text { criterin to be maximized } \\
\frac{\max _{i q}\left(a_{i k}^{q}\right)-a_{i k}^{q}}{\max _{i q}\left(a_{i k}^{q}\right)-\min _{i q}\left(a_{i k}^{q}\right)} \text { for the } \mathrm{k}^{\text {th }} \text { criterion to be minimized }
\end{array},\right.
$$

where $\max _{i q}\left(a_{i k}^{q}\right)$ and $\min _{i q}\left(a_{i k}^{q}\right)$ are the maximum and minimum values of the $\mathrm{k}^{\text {th }}$ drought index in $\mathrm{q}^{\text {th }}$ neighborhood.

The degree of ORness was used to measure the weighting vector of the OWA operator. The degree of ORness is given as below (Yager, 1993):

$$
\alpha=\sum_{k=1}^{n} \frac{n-k}{n-1} \lambda_{k}, 0 \leq \text { ORness } \leq 1
$$

where $\alpha$ measures the degree of similarity of OWA operator to the logical OR operator. If the value of $\alpha=0.5, \lambda_{k}=1 / \mathrm{n}$; when $\alpha=0, \lambda_{k}=1$ and all other weights are 0 ; and if $\alpha=1$ for $\lambda_{n}=1$, all other $\lambda_{k}$ weights are equal to 0 . Table 3 shows the values of $\lambda_{k}$ for different values of $\alpha$. The normalized form of the dispersion is given as below:

$$
\varphi=-\sum_{k=1}^{n} \frac{\lambda_{k} \ln \lambda_{k}}{\ln n}
$$

where $\varphi$ indicates order weight dispersion. $0 \leq \varphi \leq 1 ; \varphi=0$ for $\lambda_{k}=1$ and all other weights are 0 ; the value of $\varphi=1$ for all $\lambda_{k}=1 / \mathrm{n}$. The order weights $\lambda_{k}$ could be obtained by solving the following non-linear equation: 


$$
\operatorname{maximize} \varphi=-\sum_{k=1}^{n} \frac{\lambda_{k} \ln \lambda_{k}}{\ln n}
$$

subject to:

$$
\sum_{k=1}^{n} \frac{n-k}{n-1} \lambda_{k}=\alpha, \sum_{k=1}^{n} \lambda_{k}=1,0 \leq \lambda_{k} \leq 1, \text { for } k=1,2, \ldots, n
$$

Table 3 Optimal order weights $\left(\lambda_{k}\right)$ for selected values of the $\alpha$ parameter and the number of criteria $n=4$.

\begin{tabular}{rrrrrrrrrrrr}
\hline$\alpha$ & 0 & 0.1 & 0.2 & 0.3 & 0.4 & 0.5 & 0.6 & 0.7 & 0.8 & 0.9 & 1 \\
\hline$\lambda_{1}$ & 0 & 0.084 & 0.117 & 0.135 & 0.167 & 0.250 & 0.347 & 0.405 & 0.494 & 0.491 & 1 \\
$\lambda_{2}$ & 0 & 0.150 & 0.179 & 0.209 & 0.213 & 0.250 & 0.273 & 0.284 & 0.284 & 0.308 & 0 \\
$\lambda_{3}$ & 0 & 0.272 & 0.280 & 0.286 & 0.272 & 0.250 & 0.214 & 0.171 & 0.157 & 0.163 & 0 \\
$\lambda_{4}$ & 1 & 0.494 & 0.424 & 0.363 & 0.347 & 0.250 & 0.166 & 0.140 & 0.066 & 0.041 & 0 \\
\hline
\end{tabular}

The $\alpha$ parameter indicates the position of OWA on a continuum between the AND and OR operators (Malczewski and Liu, 2014; Tang et al., 2018). Here, to investigate the effect of the analyst's risk attitude on the drought conditions, nine different risk attitudes of local OWA with $\alpha=$ 0.1, 0.2, 0.3, 0.4, 0.5,0.6, 0.7, 0.8 and 0.9 were evaluated by in-situ drought indices. From the different $\alpha$ profiles tested, the local OWA with $\alpha=0.3$ showed the best correlation with SPI, PDSI, and Zindices of various timescales (see Table.4). $\alpha=0.3$ was recommended for establishment of GIIDI.

Table 4 Correlation coefficients (r-values) between in situ drought indices (PDSI, Z-index and SPIs of different timescales) and local OWAs with different $\alpha$ values. $\mathrm{p}<0.01$ in all cases. ${ }^{*}$ denotes the largest $\mathrm{r}$-value for each drought index weighting.

\begin{tabular}{cllllll}
\hline & \multicolumn{6}{c}{ r-value } \\
\cline { 2 - 7 }$\alpha$ & PDSI & Z-index & SPI-1 & SPI-2 & SPI-3 & SPI-6 \\
\hline 0.1 & 0.602 & 0.694 & 0.728 & 0.746 & 0.712 & 0.628 \\
0.2 & 0.693 & 0.698 & 0.732 & 0.760 & 0.726 & $0.639^{*}$ \\
0.3 & $0.701^{*}$ & $0.794^{*}$ & $0.811^{*}$ & $0.786^{*}$ & $0.733^{*}$ & 0.628 \\
0.4 & 0.660 & 0.695 & 0.727 & 0.757 & 0.724 & 0.638 \\
0.5 & 0.656 & 0.694 & 0.721 & 0.751 & 0.719 & 0.633 \\
0.6 & 0.690 & 0.683 & 0.712 & 0.724 & 0.693 & 0.613 \\
0.7 & 0.694 & 0.690 & 0.721 & 0.740 & 0.707 & 0.621 \\
0.8 & 0.684 & 0.691 & 0.727 & 0.734 & 0.699 & 0.612 \\
0.9 & 0.681 & 0.680 & 0.711 & 0.716 & 0.684 & 0.604 \\
\hline
\end{tabular}




\subsection{Accuracy assessment}

We evaluated GIIDI in three steps. First, we evaluated the indices using data from the growing seasons (April-October) of 2007, 2009 and 2011, which were generally categorized as severe drought, moderate drought and extreme drought years. The drought conditions estimated from GIIDI were compared to drought status from SDCI, MIDI, OMDI and USDM. USDM was used as a standard for the comparison. OMDI, MIDI and SDCI were chosen to compare with GIIDI due to their relatively good performance in other work (Zhang et al. 2017a). Our analysis at this stage was largely qualitative. In the second stage, the correlation values (r-value) and the root mean square error (RMSE) between GIIDI and in-situ drought indices were used to examine the performance of GIIDI. We also provided an uncertainty assessment by evaluating the linear regression prediction interval based on the following equation:

$$
\hat{y}_{h} \pm t \frac{a}{2}, n-2 \sqrt{M S E\left(1+\frac{1}{N}+\frac{\left(x_{n e w}-\bar{x}\right)^{2}}{\sum\left(x_{k}-\bar{x}\right)^{2}}\right)}
$$

where $\hat{y}_{h}$ is the fitted response at predictor drought index value $x_{k}$ and the critical t-value is $t_{\frac{a}{2}, n-2}$ with n-2 degrees of freedom. $\left.\sqrt{\operatorname{MSE}\left(1+\frac{1}{N}+\frac{\left(x_{k}-\bar{x}\right)^{2}}{\sum\left(x_{k}-\bar{x}\right)^{2}}\right.}\right)$ is the standard error of prediction. A 95\% level of confidence was used. The prediction uncertainty interval of GIIDI was compared with each drought index. 


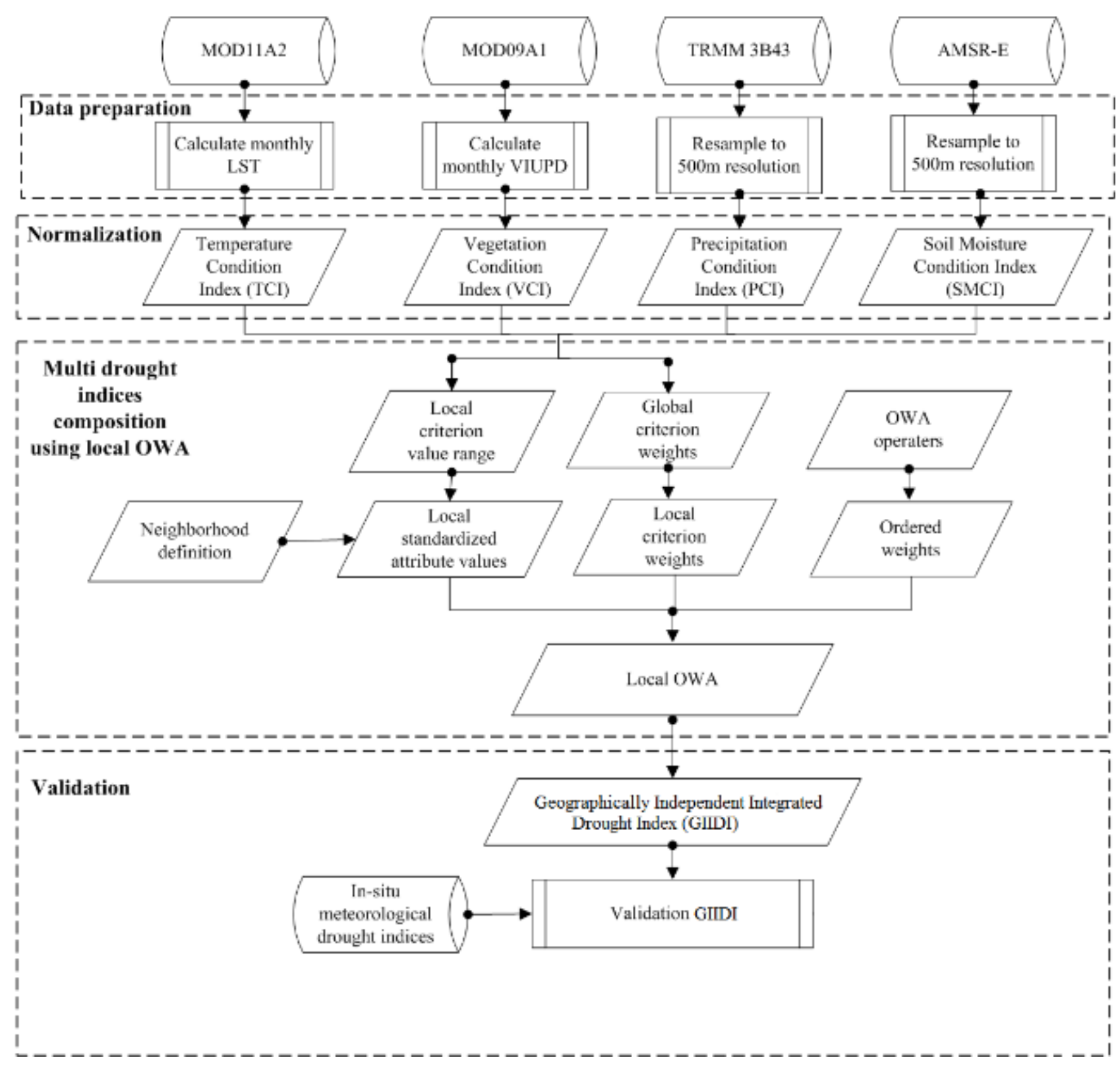

Fig. 1 Flowchart of comprehensive drought estimation based on multi-source remote sensing data.

\section{Results}

\subsection{Regional drought pattern comparisons}

The growing seasons of 2007, 2009 and 2011 were selected to evaluate the spatial variation of GIIDI and other drought indices. In 2011, many parts of the U.S., and especially Texas, experienced one of the most extreme droughts in the historical record (Long et al., 2013). Similarly, in 2007, much of the U.S. experienced a severe drought event, and in 2009, much of the country experienced 17 
moderate drought conditions. Figs. 2-4 show the variation among the indices for 2011, 2009 and 2007, respectively. According to Fig. 2 to Fig. 4, by visual comparison, GIIDI generally shows greater similarity to USDM under all drought conditions than other drought indices.

For the extreme drought year of 2011, drought conditions were initially located in much of Texas, New Mexico in April, then expanded north and east throughout the summer (see USDM in Fig. 2). OMDI, SDCI, MIDI and GIIDI all indicated extreme drought conditions from April to May in the South. However, SDCI, OMDI and MIDI also showed expansion of the extreme drought to parts of the Great Plains and the Northwestern CONUS in June, while these regions were not confirmed to be experiencing extreme drought conditions by USDM. GIIDI estimated the drought to be much more confined, and did not indicate extreme drought in the Plains or Northwestern U.S.

For the moderate drought year of 2009, the USDM indicated moderate drought in Western regions along the coast, and a small region of extreme drought in south Texas (Fig. 3). GIIDI described the spatial extent of the drought better than other drought indices, using USDM as the reference. In general, other drought indices overestimated the drought conditions across the CONUS. For example, from April to May, these three indices showed large regions under extreme drought conditions in the Northwestern Great Plains. In June, these three indices indicated that the severe drought areas were mainly located Northern and Southeastern regions. In September, they indicated the severe drought areas were mainly located in the West and Northeastern CONUS, in contrast to estimate from USDM and GIIDI.

In 2007, USM indicated that drought conditions were mainly located in Western regions and parts of the Southeast (Fig 4). Similar to the year of 2009 and 2011, GIIDI was more consistent with USDM than the other three indices, which generally overestimated the drought severity. For SDCI, MIDI and OMDI, extreme drought appeared in May in the Eastern and Western CONUS. In October, the severe drought appeared in Southwestern regions such as Arizona, New Mexico and part of Texas. However, USDM and GIIDI showed only moderate or slight drought conditions in these regions. It was even more obvious that in October 2007, SDCI, MIDI and OMDI over-estimated drought 
conditions in the Southwest, where drought was not detected by USDM.

USDM

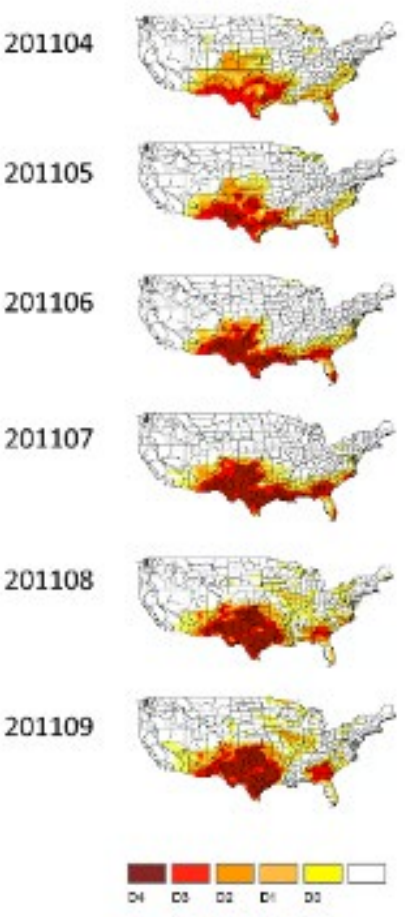

GIIDI
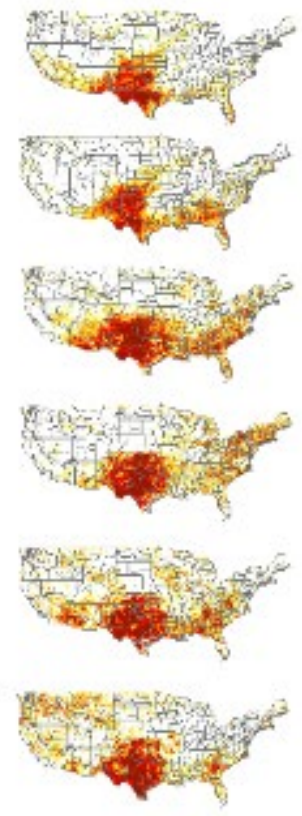

0.050 .100 .150 .200 .25
OMDI
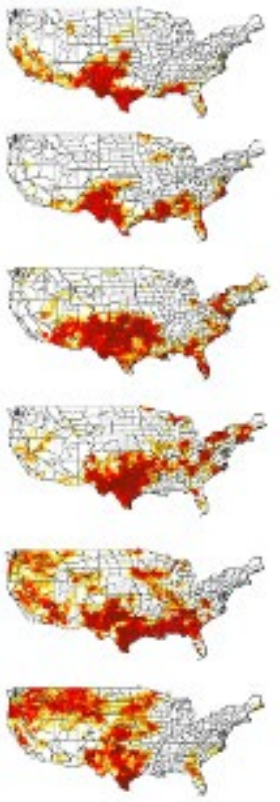

a.2. a.10 0.15 0.20 0.25
SDCI

MIDI
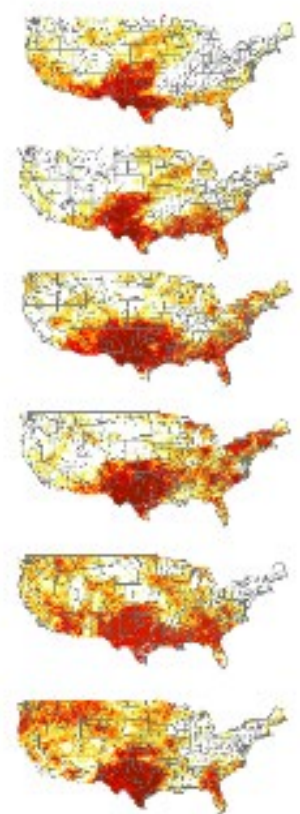

0.200 .200300400 .59
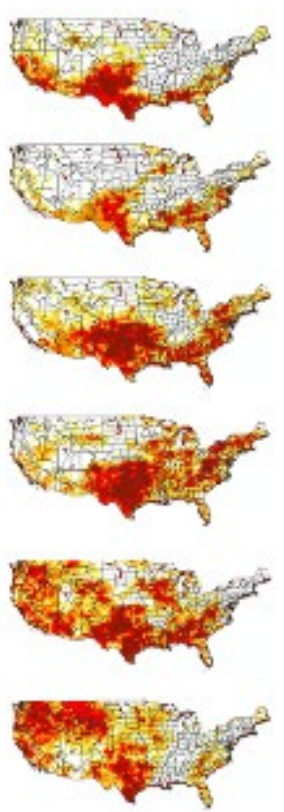

0.050 .200 .300 .400 .50

Fig. 2 Drought conditions in the US monitored by multiple drought indices from April to September, 2011. The first column displays the observed USDM drought data, while the second to fifth columns show the GIIDI, OMDI, SDCI and MIDI, respectively. For USDM, D0-D4 represents the different severities of drought conditions; for columns 2 to 5 , lower values stand for more severe drought. 


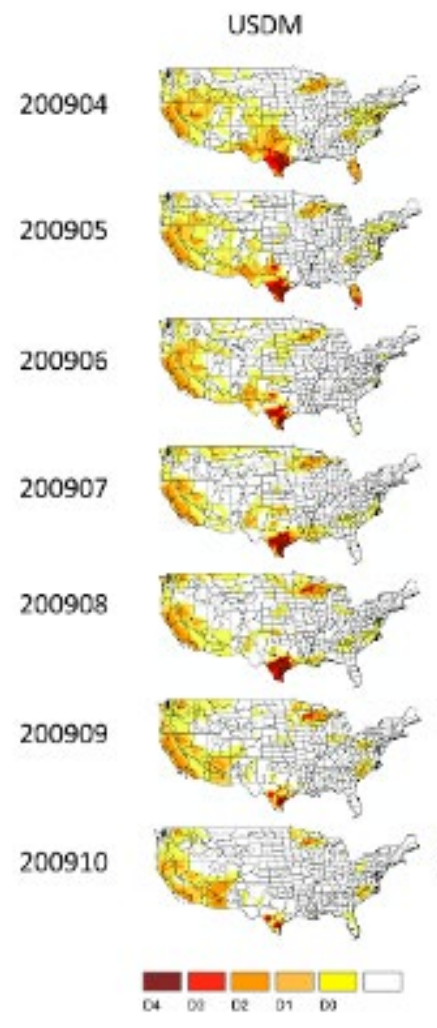

(a)
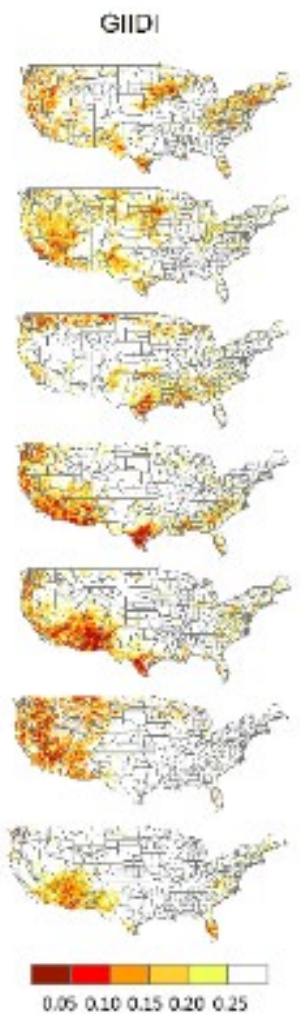

(b)
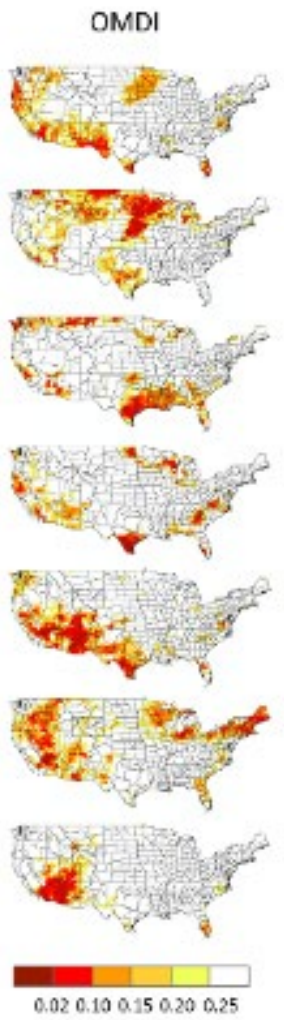

(c)
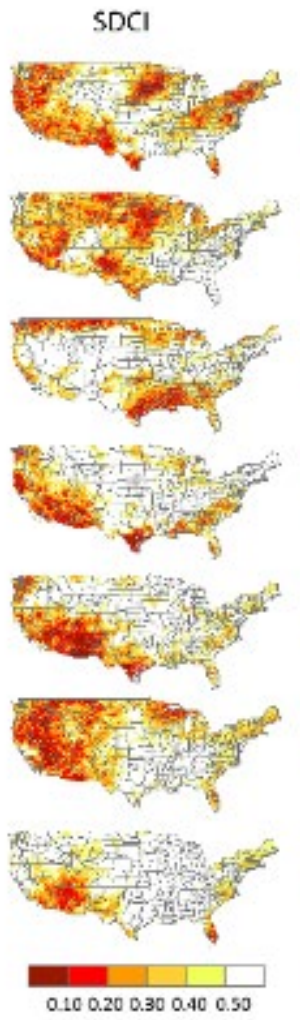

(d)

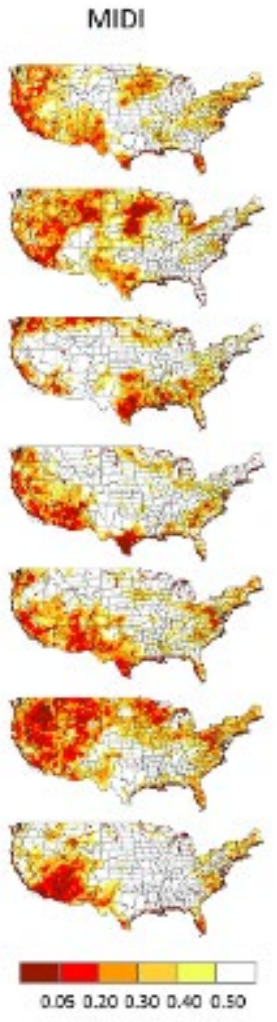

(e)

Fig. 3 Same as Figure 2, but for the period from April to October in 2009. 


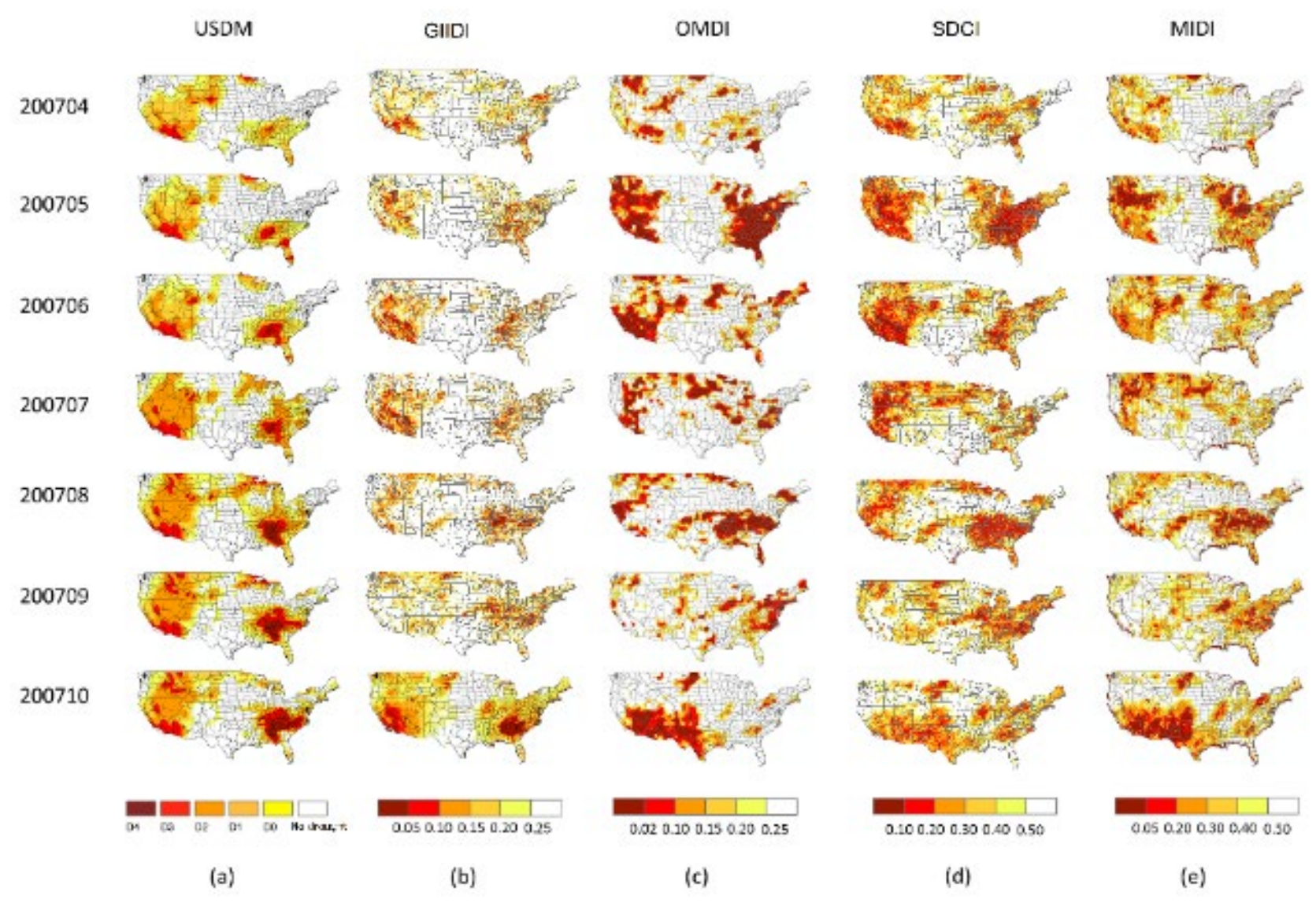

Fig. 4 Same as Fig.2 and Fig.3, but for the period from April to October in 2007.

\subsection{Monthly temporal correlation comparisons}

We compared the correlations between seven remotely sensed drought indices (GIIDI, MIDI, OMDI, PCI, TCI, VCI and SMCI) and in-situ drought indices (PDSI, Z-Index, 1-, 3-, 6-month SPI). Among the seven remotely sensed drought indices compared, GIIDI has superior performance than other indices in most goodness-of-fit measures. As shown in Table 5, GIIDI was more closely correlated with PDSI, Z-index, 1-, 3-, 6-month SPI ( $\mathrm{r}=0.701,0.794,0.811,0.733,0.628$, respectively, $\mathrm{p}<0.05$ for all cases) when compared with MIDI, OMDI, VCI, PCI, TCI and SMCI. Table 6 shows that GIIDI had smaller RMSE (RMSE $=1.979,0.810,0.729,1.049,1.071$, respectively) when compared with MIDI, OMDI, VCI, PCI, TCI and SMCI. GIIDI also showed lower prediction uncertainty than other drought indices when compared with in-situ drought indices (e.g., PDSI, Z- 
index, SPI-1, SPI-3 and SPI-6). Fig. 5 presents an example of the uncertainty range for predicting drought intensity using PDSI as "true values". The prediction interval for GIIDI was significantly narrower than MIDI, OMDI, VCI, PCI, TCI and SMCI. Similar patterns are shown in supplementary Fig. 1 when using Z-index, SPI-1, SPI-3 and SPI-6 as drought intensity "true values".

Table 5 Comparison of the performance of GIIDI and six other commonly used remote sensing drought indices using 6 in-situ drought indexes as a reference. $\mathrm{r}$ is the correlation coefficient between two variables. *denotes the minimum maximum value in each column. GIIDI, MIDI, OMDI, PCI, TCI, VCI and SMCI are seven remotely sensed drought indices; PDSI, Z-Index, 1-, 3-, 6-month SPI are in-situ drought indices. *denotes the maximum value in each column.

\begin{tabular}{llllll}
\hline \multirow{2}{*}{$\begin{array}{l}\text { Drought } \\
\text { indices }\end{array}$} & \multicolumn{5}{c}{$\mathrm{r}(\mathrm{n}=24080)$} \\
\cline { 2 - 6 } GIIDI & PDSI & Z-index & SPI-1 & SPI-3 & SPI-6 \\
OMDI & $0.701^{*}$ & 0.794 & 0.811 & $0.733^{*}$ & $0.628^{*}$ \\
MIDI & 0.496 & $0.825^{*}$ & $0.871^{*}$ & 0.686 & 0.592 \\
VCI & 0.504 & 0.788 & 0.807 & 0.662 & 0.580 \\
PCI & 0.622 & 0.313 & 0.234 & 0.564 & 0.582 \\
TCI & 0.440 & 0.806 & 0.865 & 0.559 & 0.398 \\
SMCI & 0.542 & 0.589 & 0.487 & 0.515 & 0.471 \\
\hline
\end{tabular}

Table 6 Comparisons of the RMSE between GIIDI and other commonly used remote sensing based drought indices. *denotes the minimum maximum value in each column. GIIDI, MIDI, OMDI, PCI, TCI, VCI and SMCI are seven remotely sensed drought indices; PDSI, Z-Index, 1-, 3-, 6-month SPI are in-situ drought indices. *denotes the minimum value in each column.

\begin{tabular}{llllll}
\hline \multirow{2}{*}{$\begin{array}{l}\text { Drought } \\
\text { indices }\end{array}$} & PDSI & Z-index & SPI-1 & SPI-3 & SPI-6 \\
\cline { 2 - 6 } GIIDI & $1.979^{*}$ & 0.810 & $0.729^{*}$ & $1.049^{*}$ & $1.071^{*}$ \\
OMDI & 3.011 & $0.803^{*}$ & 0.732 & 1.305 & 1.805 \\
MIDI & 2.985 & 0.823 & 0.776 & 1.344 & 1.878 \\
VCI & 2.658 & 2.244 & 1.159 & 1.075 & 1.082 \\
PCI & 3.440 & 0.865 & 0.801 & 2.559 & 2.598 \\
TCI & 2.709 & 2.289 & 1.166 & 1.145 & 1.271 \\
SMCI & 2.856 & 2.234 & 1.183 & 1.324 & 1.245 \\
\hline
\end{tabular}



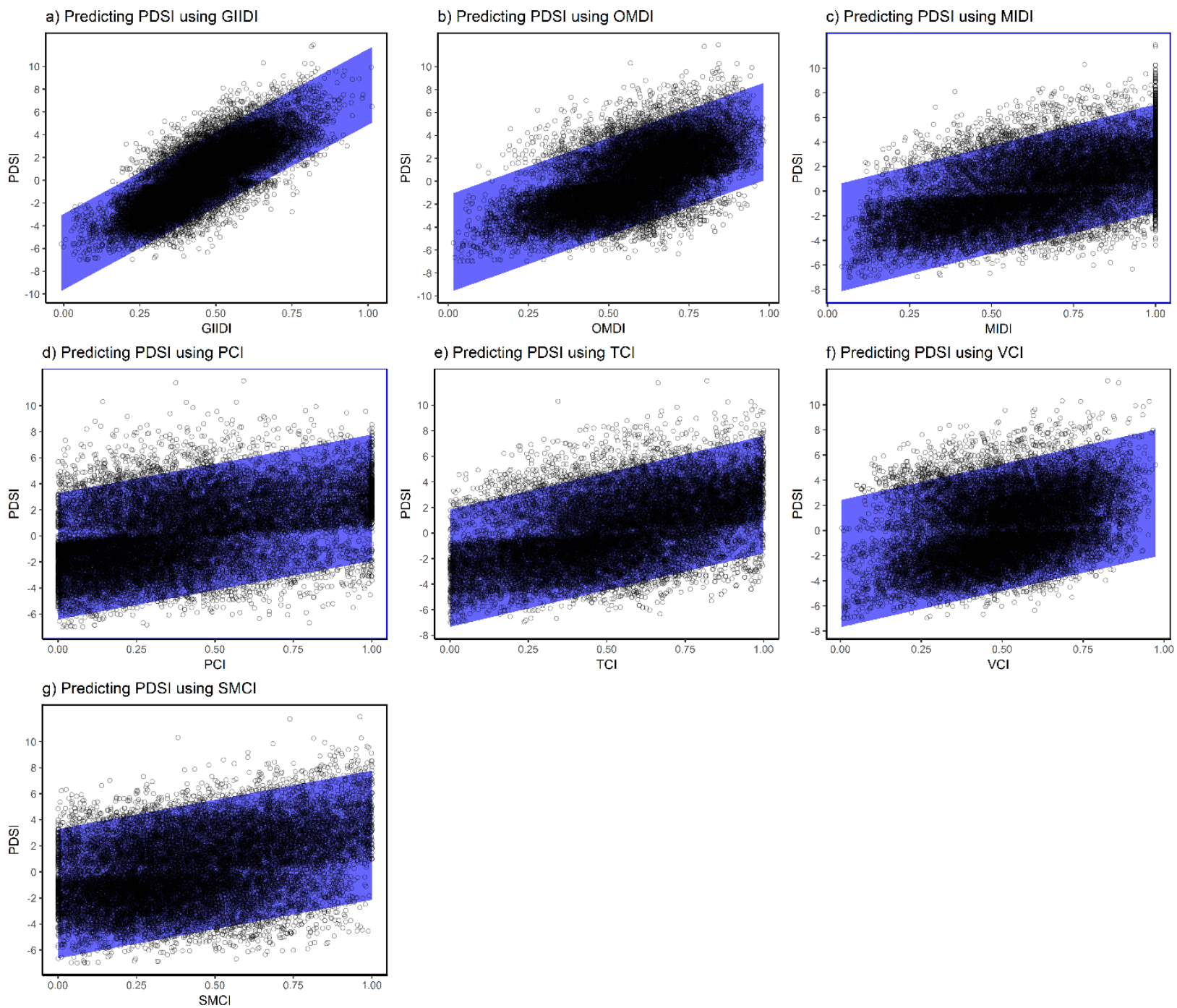

Fig. 5 Prediction interval for the compared drought indices when using PDSI as "true values". The shaded area indicates the $95 \%$ prediction interval for each drought index.

\subsection{Spatial variability comparisons}

Spatially, GIIDI produced stronger correlations with PDSI, Z-index, SPI-1, SPI-3 and SPI-6 than other remote sensing-based indices in almost all the climate divisions (Fig. 6), with correlation values (r) usually $>0.6$. VCI was generally correlated only with long term in-situ drought indices (PDSI, 3and 6-month SPI), with the strongest correlations limited to the Southeastern US. Both MIDI and OMDI only have good performance when correlated to short-term drought indices (Z-index and 1month SPI). PCI exhibited stronger correlations with SPI-1. However, the correlations of PCI and long-term SPI (SPI-3 and SPI-6) were low in most of the CONUS. TCI and SMCI generally had similar performance. They showed stronger correlation with in-situ indices than the short-term SPI 
indices but weak correlations with PDSI and long-term SPIs (3- and 6-SPI) for most areas.

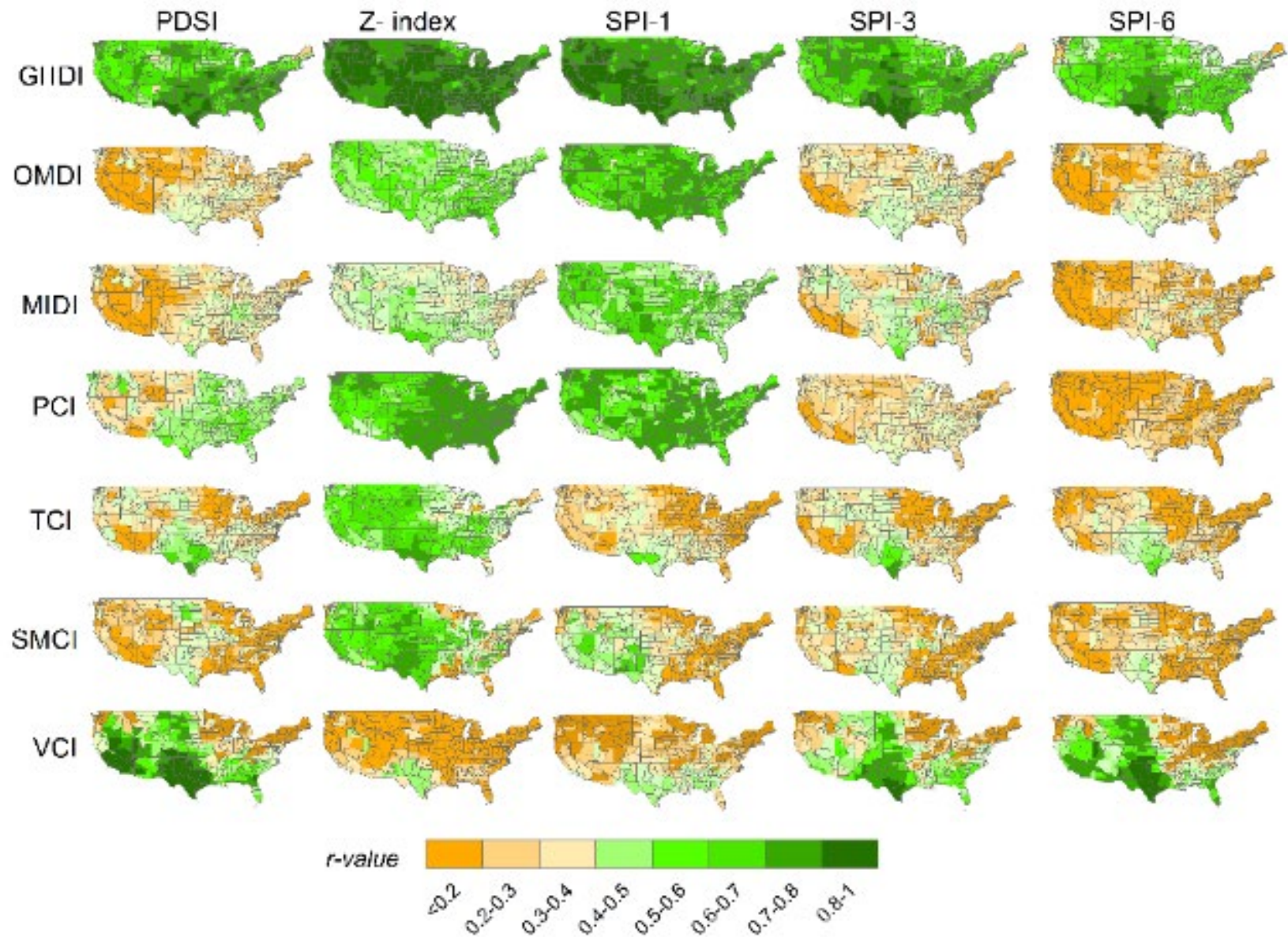

Fig. 6 Spatial distribution of climate divisions with the correlations (r-value) between remote-sensing-based and insitu-based drought indices for the entire growing season (April to October) of 2002-2011.

\section{Discussion}

Our overall goal was to facilitate drought detection and planning by developing an integrated, holistic drought index that can be applied across broad spatial gradients, and that doesn't rely on station data. In some ways, our new product (GIIDI) can be viewed as a remote-sensing analogue to the USDM, in that it integrates multiple sources of information describing different aspects of meteorological, agricultural, and hydrologic drought. Based on multiple comparisons, GIIDI is shown to have better performance in drought monitoring than MIDI, OMDI and other single remote sensing 
based indices across the CONUS. There are several reasons for the good performance of GIIDI. First, empirical linear combination approaches to build combined drought indices may not be applicable for the regions where the relationship between variables is spatially nonstationary, since it may miss significant local detail. In contrast, the local OWA model, in which the local criterion weight depends upon the local range, has the potential to provide a more appropriate basis for spatial integration. To illustrate the advantages of the local OWA model, we take one of the most severe drought months -August 2011-- as an example. As illustrated in Fig. 7, GIIDI more accurately estimates drought conditions than OMDI, MIDI and SDCI. OMDI, MIDI and SDCI all indicated large regions in the Northern U.S experienced severe drought - a result that was not indicated by USDM (Fig. 2) and GIIDI. The weighting of PCI, TCI, VCI and SMCI are spatially nonstationary (Fig. 7 e-i), and the weighting of each index was not the same over the whole CONUS. For example, in the most of the Great Plains, VCI takes higher weighting than other indices, but in the Northeastern regions, the weighting of VCI is lower than other indices. The embrace of different character and applicability of different single drought index by assigning spatial and temporal variable weights using the OWA model strengthened the spatial drought representation of GIIDI. 


\section{a) GIIDI}

b) MIDI
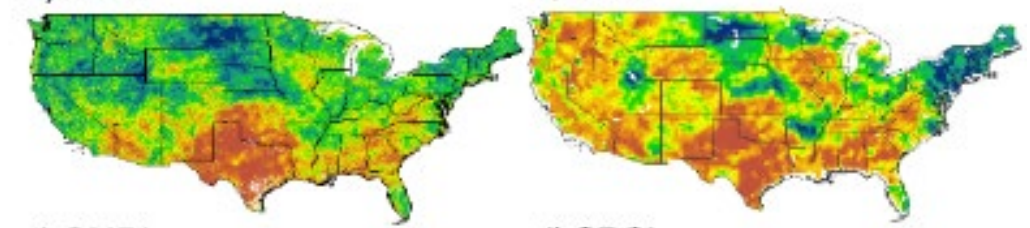

c) OMDI

d) $\mathrm{SDCl}$
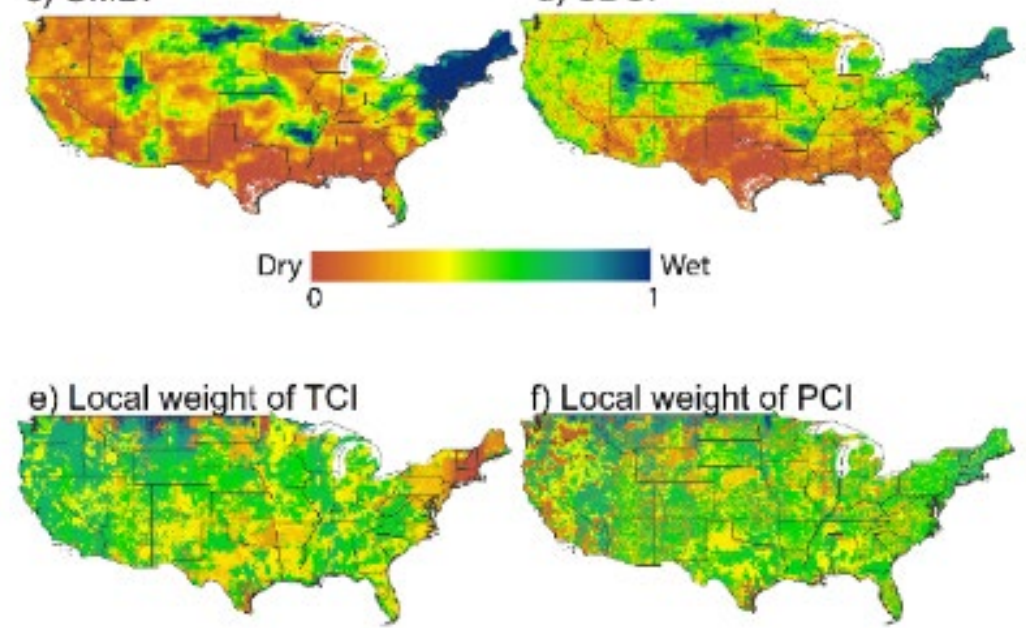

f) Local weight of $\mathrm{PCl}$

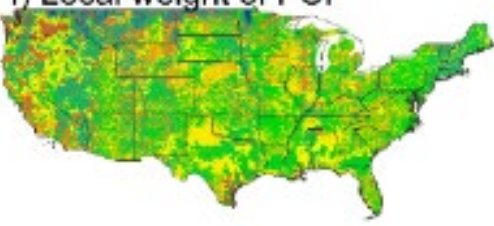

g) Local weight of $\mathrm{SMCl}$

i) Local weight of $\mathrm{VCl}$

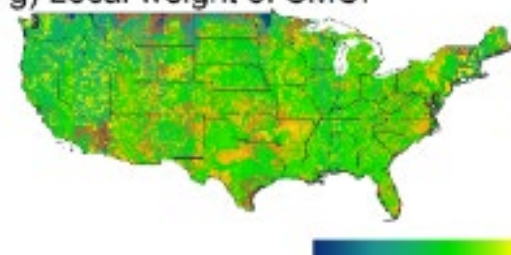

\section{the Leme}

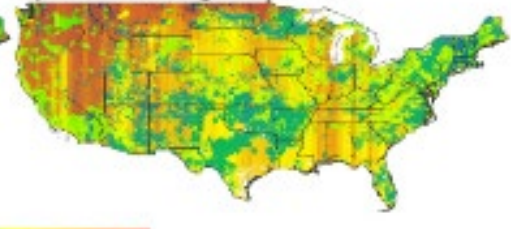

0

0.6

Fig. 7 Spatial distributions of drought conditions estimated by compared remote sensing based drought indices and local criterion weights for GIIDI establishment in August 2011: (a) GIIDI; (b) MIDI; (c) OMDI; (d) SDCI; (e) local weight of TCI; (f) local weight of PCI; (g) local weight of SMCI; (i) local weight of VCI.

Second, our choice of single indices to composite into the GIIDI may explain its relatively good performance. A previous study indicated that some condition indices (e.g., TCI, VCI, PCI and SMCI) have better performance than other drought indexes (Zhang et al., 2017a). It also indicated that the VUA-based SMCI performed better than National Snow and Ice Data Center (NSIDC)-based SMCI, and MODIS-based TCI performed better than VUA based TCI. In addition, Jiao et al. (2016) indicated that VIUPD-based VCI could improve the applicability of drought monitoring when compared to NDVI-based VCI. Informed by these, we used the MODIS LST-data based TCI, VUA-based SMCI, VIUPD-based VCI and TRMM-based PCI as the single indices to develop GIIDI. 
Our results suggest GIIDI could be a reliable index for drought monitoring across wide climate gradients. Previous work indicated that the performances of traditional remote sensing based indices, such as VCI, depend on precipitation, land cover and other factors (Bayarjargal et al., 2006; Quiring and Ganesh, 2010; Singh et al., 2003; Vicente-Serrano, 2007). As a result, many remote sensing based indices have limited applicability across different regions. For example, all fifteen remote sensing based drought indices compared in the study of Zhang et al. (2017a) performed well for Texas and other parts of the central CONUS, but did not perform well in Western and Northeastern regions. Compared with these indices, GIIDI can perform reasonably well across different climate regions. Additionally, in contrast with USDM, GIIDI does not require expert knowledge or station-based point information.

Despite all the advantages, there are some limitations that could affect the performance of GIIDI. First of all, there is no absolute "true" drought measure. By using USDM, SPI, PDSI and Z-index as the reference, we establish a benchmark for comparisons but cannot provide a true validation of GIIDI. Another limitation concerns the classification of GIIDI drought, which was based on an empirical comparison between GIIDI and USDM. Future work could focus on quantitative determination of the drought severity classification of GIIDI.

\section{Conclusions}

This study developed a new integrated drought index (GIIDI) using the local OWA model to integrate multi-sensor remote sensing data based drought indices. The remote sensing based drought indices (GIIDI, OMDI, MIDI, SDCI, MODIS-derived VCI, MODIS based TCI, TRMM based PCI, and AMSR-E based SMCI) were compared with the in-situ drought indices (PDSI, Z-index, SPI-1, SPI-3, SPI-6).

When compared to the other remote-sensing based indices, GIIDI had the strongest correlation with in-situ drought indices in most climate divisions. GIIDI effectively combines drought 
information from different single drought indices, thereby overcoming some of the shortcomings of single drought indices, which cannot always capture aspects of agricultural and meteorological drought that are of interest to land managers. Because it does not rely on expert knowledge or station data, it has strong potential to improve "holistic" drought monitoring in areas without robust meteorological station networks, and across diverse climate conditions.

\section{Acknowledgments}

We acknowledge support from Division of Earth Sciences of National Science Foundation (NSF EAR-1554894) and from the Agriculture and Food Research Initiative program (2017-67013-26191) of the USDA National Institute of Food and Agriculture.

\section{References}

AghaKouchak, A., 2015. A multivariate approach for persistence-based drought prediction: Application to the 20102011 East Africa drought, Journal of Hydrology, pp. 127-135.

AghaKouchak, A. et al., 2015. Remote sensing of drought: Progress, challenges and opportunities. Reviews of Geophysics, 53(2): 452-480.

AghaKouchak, A., Mehran, A., Norouzi, H. and Behrangi, A., 2012. Systematic and random error components in satellite precipitation data sets. Geophysical Research Letters, 39(9).

Almeida, A.C. and Landsberg, J.J., 2003. Evaluating methods of estimating global radiation and vapor pressure deficit using a dense network of automatic weather stations in coastal Brazil. Agricultural and Forest Meteorology, 118(3-4): 237-250.

Anderson, M.C. et al., 2016. The Evaporative Stress Index as an indicator of agricultural drought in Brazil: An assessment based on crop yield impacts. Remote Sensing of Environment, 174: 82-99.

Bayarjargal, Y. et al., 2006. A comparative study of NOAA-AVHRR derived drought indices using change vector analysis. Remote Sensing of Environment, 105(1): 9-22.

Brown, J.F., Wardlow, B.D., Tadesse, T., Hayes, M.J. and Reed, B.C., 2008. The Vegetation Drought Response Index (VegDRI): A new integrated approach for monitoring drought stress in vegetation. GIScience \& Remote Sensing, 45(1): 16-46.

Caccamo, G., Chisholm, L.A., Bradstock, R.A. and Puotinen, M.L., 2011. Assessing the sensitivity of MODIS to monitor drought in high biomass ecosystems. Remote Sensing of Environment, 115(10): 2626-2639.

Ciais, P. et al., 2005. Europe-wide reduction in primary productivity caused by the heat and drought in 2003. Nature, 437(7058): 529-533.

Damberg, L. and AghaKouchak, A., 2014. Global trends and patterns of drought from space. Theoretical and applied climatology, 117(3-4): 441-448.

Di, L., Rundquist, D.C. and Han, L., 1994. Modelling relationships between NDVI and precipitation during vegetative growth cycles. International Journal of Remote Sensing, 15(10): 2121-2136.

Donohue, R.J., Roderick, M.L., Mcvicar, T.R. and Farquhar, G.D., 2013. Impact of CO2 fertilization on maximum foliage cover across the globe's warm, arid environments. Geophysical Research Letters, 40(12): 3031-3035.

$\mathrm{Du}$, L. et al., 2013. A comprehensive drought monitoring method integrating MODIS and TRMM data. International Journal of Applied Earth Observation and Geoinformation, 23: 245-253.

Fischer, G.W., 1995. Range sensitivity of attribute weights in multiattribute value models. Organizational Behavior and Human Decision Processes, 62(3): 252-266.

Halwatura, D., Mclntyre, N., Lechner, A.M. and Arnold, S., 2017. Capability of meteorological drought indices for 
detecting soil moisture droughts. Journal of Hydrology: Regional Studies: 396-412.

Hao, C., Zhang, J. and Yao, F., 2015. Combination of multi-sensor remote sensing data for drought monitoring over Southwest China. International Journal of Applied Earth Observation and Geoinformation, 35: 270-283.

Hao, Z. and Aghakouchak, A., 2013. Multivariate Standardized Drought Index: A parametric multi-index model. Advances in Water Resources, 57(9): 12-18.

Hao, Z. and Singh, V.P., 2015. Drought characterization from a multivariate perspective: A review. Journal of Hydrology, 527: 668-678.

Hao, Z., Yuan, X., Xia, Y., Hao, F. and Singh, V.P., 2017. An overview of drought monitoring and prediction systems at regional and global scales. Bulletin of the American Meteorological Society(2017).

Hayes, M.J., Svoboda, M.D., Wardlow, B.D., Anderson, M.C. and Kogan, F., 2012. Drought monitoring: Historical and current perspectives.

Hielkema, J., Prince, S. and Astle, W., 1986. Rainfall and vegetation monitoring in the savanna zone of the Democratic Republic of Sudan using the NOAA Advanced Very High Resolution Radiometer. International Journal of Remote Sensing, 7(11): 1499-1513.

Hong, Y., Hsu, K.I., Moradkhani, H. and Sorooshian, S., 2006. Uncertainty quantification of satellite precipitation estimation and Monte Carlo assessment of the error propagation into hydrologic response. Water resources research, 42(8).

Ji, L. and Peters, A.J., 2003. Assessing vegetation response to drought in the northern Great Plains using vegetation and drought indices. Remote Sensing of Environment, 87(1): 85-98.

Jiao, W. et al., 2016. Evaluating an enhanced vegetation condition index based on VIUPD for drought monitoring in the continental United States. Remote Sensing, 8(3): 224.

Keyantash, J.A. and Dracup, J.A., 2004. An aggregate drought index: Assessing drought severity based on fluctuations in the hydrologic cycle and surface water storage. Water Resources Research, 40(9).

Kogan, F., 1995a. Application of vegetation index and brightness temperature for drought detection. Advances in Space Research, 15(11): 91-100.

Kogan, F.N., 1995b. Droughts of the late 1980s in the United States as derived from NOAA polar-orbiting satellite data. Bulletin of the American Meteorological Society, 76(5): 655-668.

Kogan, F.N., 1997. Global drought watch from space. Bulletin of the American Meteorological Society, 78(4): 621-636.

Long, D. et al., 2013. GRACE satellite monitoring of large depletion in water storage in response to the $2011 \mathrm{drought}$ in Texas. Geophysical Research Letters, 40(13): 3395-3401.

Lu, X., Wang, L., Pan, M., Kaseke, K.F. and Li, B., 2016. A multi-scale analysis of Namibian rainfall over the recent decadeComparing TMPA satellite estimates and ground observations. Journal of Hydrology: Regional Studies, 8: 59-68.

Malczewski, J. and Liu, X., 2014. Local ordered weighted averaging in GIS-based multicriteria analysis. Annals of GIS, 20(2): 117-129.

Mishra, A.K. and Singh, V.P., 2010. A review of drought concepts. Journal of Hydrology, 391(1): 202-216.

Mk, V.D.M. et al., 2011. Drought and ecosystem carbon cycling. Agricultural \& Forest Meteorology, 151(7): $765-773$.

Novick, K.A. et al., 2016. The increasing importance of atmospheric demand for ecosystem water and carbon fluxes. Nature Climate Change, 6(11): 1023-1027.

Pandey, S., Bhandari, H.S. and Hardy, B., 2007. Economic costs of drought and rice farmers' coping mechanisms: a crosscountry comparative analysis. Int. Rice Res. Inst.

Parida, B.R., Collado, W.B., Borah, R., Hazarika, M.K. and Samarakoon, L., 2008. Detecting Drought-Prone Areas of Rice Agriculture Using a MODIS-Derived Soil Moisture Index. Giscience \& Remote Sensing , 45(1): 109-129.

Park, S., Im, J., Jang, E. and Rhee, J., 2016. Drought assessment and monitoring through blending of multi-sensor indices using machine learning approaches for different climate regions. Agricultural and forest meteorology, 216: 157169.

Park, S., Im, J., Park, S. and Rhee, J., 2017. Drought monitoring using high resolution soil moisture through multi-sensor satellite data fusion over the Korean peninsula. Agricultural and Forest Meteorology, 237: 257-269.

Quiring, S.M. and Ganesh, S., 2010. Evaluating the utility of the Vegetation Condition Index (VCl) for monitoring meteorological drought in Texas. Agricultural and Forest Meteorology, 150(3): 330-339.

Rajsekhar, D., Singh, V.P. and Mishra, A.K., 2015. Multivariate drought index: An information theory based approach for integrated drought assessment. Journal of Hydrology, 526(s 11-12): 164-182.

Rhee, J. and Im, J., 2017. Meteorological drought forecasting for ungauged areas based on machine learning: Using longrange climate forecast and remote sensing data. Agricultural and Forest Meteorology, 237: 105-122.

Rhee, J., Im, J. and Carbone, G.J., 2010. Monitoring agricultural drought for arid and humid regions using multi-sensor remote sensing data. Remote Sensing of Environment, 114(12): 2875-2887.

Rouse, J.W., Haas, R.W., Schell, J.A., Deering, D.W. and Harlan, J.C., 1974. Monitoring the vernal advancement and retrogradation (Greenwave effect) of natural vegetation. NASA/GSFCT Type III final report. Nasa.

Sheffield, J., Andreadis, K.M., Wood, E.F. and Lettenmaier, D.P., 2009. Global and continental drought in the second half 
of the twentieth century: severity-area-duration analysis and temporal variability of large-scale events. Journal of Climate, 22(8): 1962-1981.

Singh, R.P., Roy, S. and Kogan, F., 2003. Vegetation and temperature condition indices from NOAA AVHRR data for drought monitoring over India. International Journal of Remote Sensing, 24(22): 4393-4402.

Stocker, B.D. et al., 2018. Quantifying soil moisture impacts on light use efficiency across biomes. New Phytologist, 218(4): 1430-1449.

Tadesse, T. et al., 2017. Building the vegetation drought response index for Canada (VegDRI-Canada) to monitor agricultural drought: first results. GIScience \& Remote Sensing, 54(2): 230-257.

Tang, Z., Zhang, H., Yi, S. and Xiao, Y., 2018. Assessment of flood susceptible areas using spatially explicit, probabilistic multi-criteria decision analysis. Journal of Hydrology.

Vetter, M. et al., 2008. Analyzing the causes and spatial pattern of the European 2003 carbon flux anomaly using seven models. Biogeosciences, 5(2): 561-583.

Vicente-Serrano, S.M., 2007. Evaluating the impact of drought using remote sensing in a Mediterranean, semi-arid region. Natural Hazards, 40(1): 173-208.

Wilhelmi, O.V. and Wilhite, D.A., 2002. Assessing vulnerability to agricultural drought: a Nebraska case study. Natural Hazards, 25(1): 37-58.

Wu, J. et al., 2013. Establishing and assessing the Integrated Surface Drought Index (ISDI) for agricultural drought monitoring in mid-eastern China. International Journal of Applied Earth Observation and Geoinformation, 23(0): 397-410.

Yager, R.R., 1993. On ordered weighted averaging aggregation operators in multicriteria decisionmaking, Readings in Fuzzy Sets for Intelligent Systems. Elsevier, pp. 80-87.

Zhang, A. and Jia, G., 2013. Monitoring meteorological drought in semiarid regions using multi-sensor microwave remote sensing data. Remote Sensing of Environment, 134: 12-23.

Zhang, L. et al., 2007. A new vegetation index based on the universal pattern decomposition method. International Journal of Remote Sensing, 28(1): 107-124.

Zhang, L., Jiao, W., Zhang, H., Huang, C. and Tong, Q., 2017a. Studying drought phenomena in the Continental United States in 2011 and 2012 using various drought indices. Remote Sensing of Environment, 190: 96-106.

Zhang, X., Chen, N., Li, J., Chen, Z. and Niyogi, D., 2017b. Multi-sensor integrated framework and index for agricultural drought monitoring. Remote Sensing of Environment, 188: 141-163.

Zhang, Y. et al., 2016. Canopy and physiological controls of GPP during drought and heat wave. Geophysical Research Letters, 43(7): 3325-3333.

Zhou, L. et al., 2012. Comparison of remotely sensed and meteorological data-derived drought indices in mid-eastern China. International Journal of Remote Sensing, 33(6): 1755-1779. 

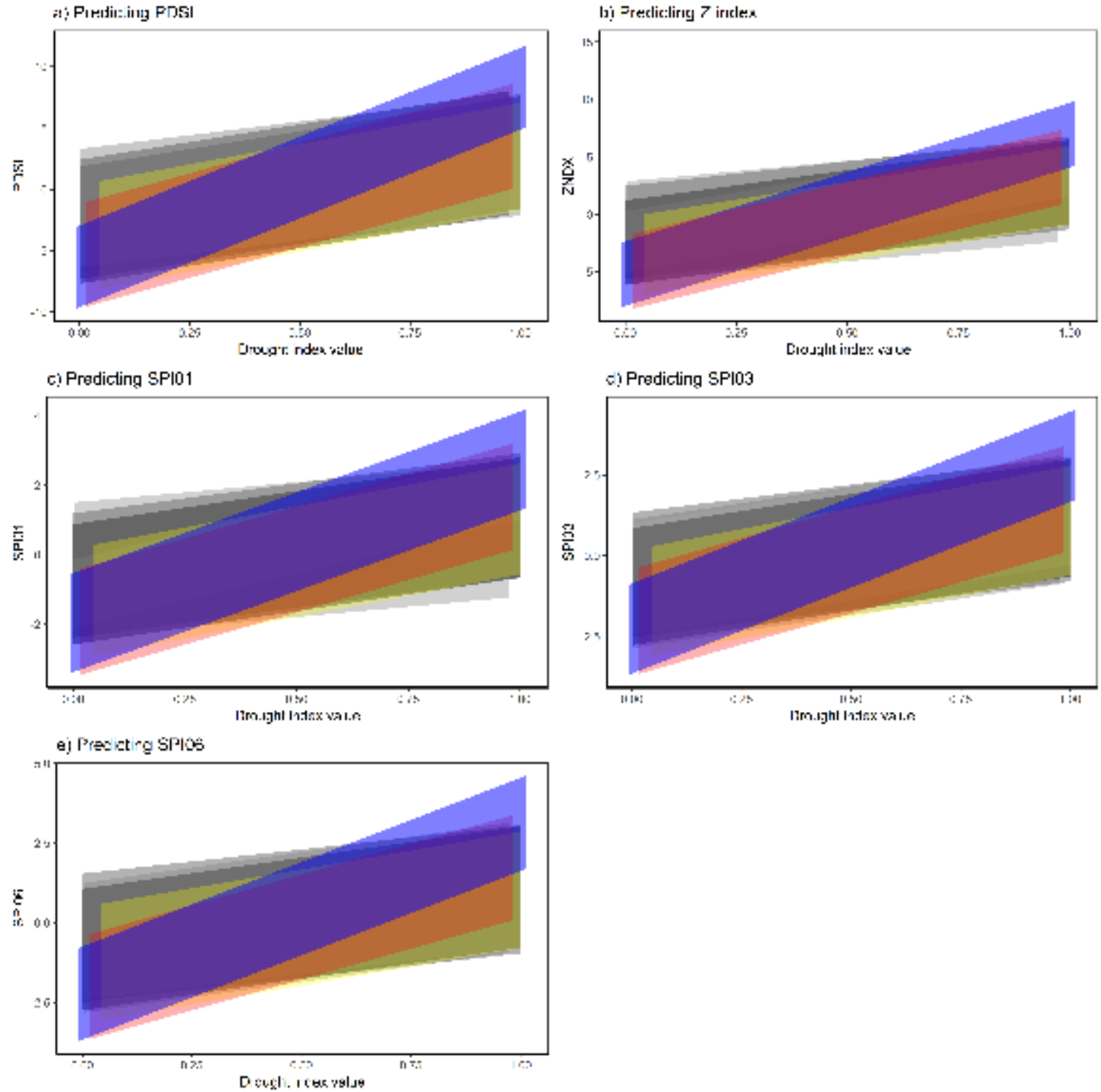

Fig. S1 The prediction intervals for the various drought indices when using PDSI, Z-index, SPI-1, SPI-3 and SPI6 as proxies. The shaded area indicates the $95 \%$ prediction interval for each drought index. Blue shade indicates the uncertainty range for GIIDI. Orange and yellow indicate uncertainty range for OMDI and MIDI. Grey colors indicate uncertainty range for the single drought indices: PCI, TCI, SMCI and VCI. 